\title{
Paper
}

\section{Empirical Analysis of Minimum Interlayer Number for Functionally Graded Materials}

\author{
Kazuhiro Hasezaki and Yasutoshi Noda \\ Department of Materials Science, Shimane University, Matsue 690-8504, Japan.
}

Received June 18, 2008

\begin{abstract}
SYNOPSIS
Minimum interlayer numbers of functionally graded materials (FGMs) is studied based on the empirical analysis of thermal stress due to the differences in the thermal expansion coefficient $\Delta \alpha$ and temperature $\Delta T$ between sintering and room temperatures. It is found the maximum $\Delta \alpha, \Delta T, \Delta \alpha \Delta T$ and the minimum interlayer number necessary to produce a $\mathrm{NiCr} / \mathrm{Fly}$ ash FGM structure without cracking are $4.0 \times 10^{-6} \mathrm{~K}^{-1}, 1080 \mathrm{~K}, 0.043$ and 2 , respectively. The criterion, $\Delta \alpha \Delta T<0.043$, is derived and confirmed to be valid for available FGM systems.

KEY WORDS

functionally graded material, thermal expansion coefficient, thermal stress, crack-free FGMs, spark plasma sintering
\end{abstract}

\section{Introduction}

Recently many studies have tried to join materials using the concept of functionally graded materials (FGMs) ${ }^{1}$. FGMs are characterized by variations in composition and microstructure that result in unique physical properties that are different from those of conventional composite materials. FGMs are defined as materials with engineered gradients of compositon, structure and/or specific properties that are superior to the properties of homogenous materials composed of the same or similar constituents. FGMs are being developed for a variety of applications including thermal resistant materials for spacecraft, tools, coatings, semiconductors, optical materials and biomaterials ${ }^{2,3)}$.

Many excellent FGMs are rather difficult and expensive in manufacturing because they need unconventional materials, and because of the lack of simple design scheme, as well as of suitable procedures for fabrication ${ }^{2,4)}$. To manufacture FGMs, it is necessary to find simple routes for creating the gradient component.

The purpose of the present study is to derive conditions for preparing stable FGMs by stepwise stacking constituent layers, where the linear thermal expansion coefficients are taken into account for an empirical bimetal model of the two adjacent layers. A condition was confirmed for flyash/NiCr FGM where the ceramics and the metal were joined by sintering without cracking. Furthermore, the derived empirical criterion could be applied to many available FGM data using the reported thermal expansion coefficients and sintering temperature.

\section{FGM Analysis Model}

An FGM structure is regarded as a layered material for which the composition is graded from material A (Young's modulus $E_{\mathrm{A}}$ and thermal expansion coefficient $\alpha_{\mathrm{A}}$ ) to B $\left(E_{\mathrm{B}}\right.$ and $\left.\alpha_{\mathrm{B}}\right)$ as shown in Fig. 1. $E$ and $\alpha$ are continuous or change stepwise in $n$ interlayers leading to the FGM concept ${ }^{1)}$ without the nonlinear properties of phase transformation and interaction between individual materials. Regarding the layered FGMs, the relationship used for a bimetal is adopted for the $i$-th and $(i+1)$-th adjacent layers. When these layers are stacked and sintered at a temperature $T_{\mathrm{s}}$, each interlayer in contact experiences

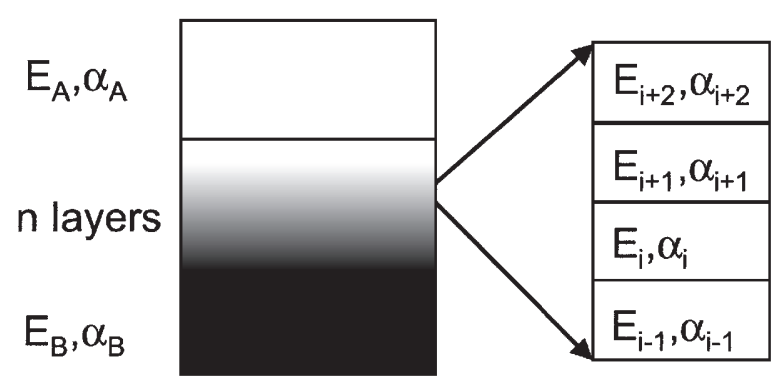

Fig.1 Analysis model of functionally graded materials. 
maximum thermal shear stresses (elongation and compression) upon cooling to room temperature $T_{0}$, the magnitudes of which can be estimated from the pertaining physical properties.

Generally, the maximum thermal shear stress $(\sigma)$ acting on the $i$-th and $(i+1)$-th layers with equal cross-sections is given by

$$
\sigma=\frac{E_{i} E_{i+1}}{E_{i}+E_{i+1}}\left(\alpha_{i}-\alpha_{i+1}\right)\left(T_{s}-T_{0}\right)
$$

In case that $E_{i}$ is set to be equal to $E_{i+1}$, equation (1) is simplified as

$$
\sigma=\frac{E}{2}\left(\alpha_{i}-\alpha_{i+1}\right)\left(T_{s}-T_{0}\right)
$$

because the mechanical properties ( $\alpha$ and $E$ ) in FGMs are almost equal in the vicinity of the $i$-th and $(i+1)$-th interlayer. Generally, the fracture stress is directly proportional to Young's modulus according to Griffith's theory. Equation (2) then becomes

$$
\frac{2 \sigma}{E}=\left(\alpha_{i}-\alpha_{i+1}\right)\left(T_{s}-T_{0}\right)=\Delta \alpha \Delta T \propto \text { const }
$$

where $\Delta \alpha$ is the difference in the linear expansion coefficient between the two adjacent interlayers and $\Delta T$ is the temperature difference between the sintering and room temperatures, respectively. The equation means $\Delta \alpha \Delta T$ is expected to be less than a fixed value, which can be estimated from experiments on the production of FGMs without interlayer fractures and cracks.

The minimum number of interlayers needed to make a crack free FGM is given by

$$
n_{\min }=\frac{\alpha_{A}-\alpha_{B}}{\Delta \alpha}
$$

where $n_{\min }$ is the integer rounded up after the decimal point of eq. (4). It is understood that the number of interfaces is $n_{\min }+1$.

$\Delta \alpha \Delta T$ was estimated for preparing FGMs using coal fly ash and $\mathrm{NiCr}$ alloy and compared with the available data for other FGMs.

\subsection{Source powders}

\section{Experimental ${ }^{5,6)}$}

Powder sources of coal fly ash and $\mathrm{NiCr}$ alloy were used for the preparation of the sintered materials ${ }^{5,6)}$. The coal fly ash, produced by Misumi Power Station (Chugoku Electric Power Co., Inc.), had an average particle size of $19 \mu \mathrm{m}$. The chemical composition of the coal fly ash, which contained about $2 \%$ carbon from unburned coal, is given in Table 1. NiCr-based alloy (Fukuda Metal Foil and Powder Co., Ltd.) was selected as a component of the joining metal powder and had an average particle size of
$65 \mu \mathrm{m}$; the chemical composition of the alloy is listed in Table 2. In preliminary studies ${ }^{6}$, uniform materials were made to measure the thermal expansion coefficients of sintered materials, where the source powders were weighed, mixed, and sintered with the volume fractions (fv) of fly-ash to the NiCr-based alloy equal to $0,0.3,0.4$, $0.5,0.6,0.7$, and 1. Pairs of layers were selected and sintered to confirm stable joining or unstable cracking during FGM preparation. Stable FGMs without interlayer cracking were prepared by sintering stacked layers with the composition of [(coal fly ash)/(coal fly ash $+0.4 \mathrm{NiCr}$ )/ (coal fly ash $+0.6 \mathrm{NiCr}) /(\mathrm{NiCr})]$.

\subsection{Spark plasma sintering}

Sintering was performed using spark plasma sintering apparatus (SS-Alloy Co., Ltd). The mixtures were stacked layer by layer, and the stacked layers were placed in a graphite die. A mechanical pressure of $50 \mathrm{MPa}$ was applied to the graphite punches. Sintering was performed at 1000 or $1100^{\circ} \mathrm{C}$ for $10 \mathrm{~min}$ in vacuum $(10 \mathrm{~Pa})$ with a pulse current $t^{5,6)}$, which was followed by cooling to room temperature in 30 $\min$.

\subsection{Characterization}

Each material that composed the FGM was preliminarily sintered and machined into test pieces $(\phi 8.0 \mathrm{~mm} \times 5.0 \mathrm{~mm})$. For the homogeneous sintered materials, metallographic investigations were made by optical microscope and the

Table 1 Chemical composition of coal fly-ash from the Misumi Power Station.

\begin{tabular}{cccc} 
Composition & \multicolumn{3}{c}{ Mass\% } \\
\hline \hline $\mathrm{SiO}_{2}$ & 63.5 & \pm & 5.1 \\
\hline $\mathrm{Al}_{2} \mathrm{O}_{3}$ & 22.5 & \pm & 3.0 \\
\hline $\mathrm{Fe}_{2} \mathrm{O}_{3}$ & 4.3 & \pm & 1.0 \\
\hline $\mathrm{CaO}$ & 1.8 & \pm & 1.3 \\
\hline $\mathrm{MgO}$ & 0.8 & \pm & 0.4 \\
\hline $\mathrm{SO}_{3}$ & 0.3 & \pm & 0.1 \\
\hline $\mathrm{Na}_{2} \mathrm{O}$ & 0.6 & \pm & 0.3 \\
\hline $\mathrm{K}_{2} \mathrm{O}$ & 1.0 & \pm & 0.3
\end{tabular}

Table 2 Chemical composition of NiCr-based alloy from Fukuda Metal Foil and Powder Co., Ltd

\begin{tabular}{cl} 
Composition & Mass\% \\
\hline \hline $\mathrm{Ni}$ & 77.8 \\
\hline $\mathrm{Cr}$ & 20.3 \\
\hline $\mathrm{C}$ & 0.01 \\
\hline $\mathrm{Si}$ & 0.99 \\
\hline $\mathrm{Mn}$ & 0.89
\end{tabular}


linear thermal expansion coefficient $\alpha$ was measured from room temperature to $750^{\circ} \mathrm{C}$ by a SHIMADZU TMA-50. The FGMs were characterized by scanning electron microscopy (SEM) (JEOL JSM-5310 at $15 \mathrm{kV}$ ) and energy dispersive X-ray (EDX) analysis (secondary electron mapping at $15 \mathrm{kV})$.

\section{Results and Discussion}

Fig. 2 shows the plots of displacement upon thermal expansion versus temperature for the materials sintered at $1000^{\circ} \mathrm{C}$ as a function of the volume fraction $\mathrm{fv}$, of the coal fly ash to $\mathrm{NiCr}$-based alloy. The displacement measured for all the homogeneous materials was found to increase almost linearly with temperature, indicating the $\alpha$ values were almost constant for the materials over the measured temperature range. The results for thermal expansion measurements support the assumption shown in Fig. 1 and eq. (4).

Fig. 3 shows a plot of the $\alpha$ values versus fv in the mixtures of coal fly ash and $\mathrm{NiCr}$-based alloy sintered at $1000^{\circ} \mathrm{C}^{6 \text { ) }}$. The $\alpha$ value was estimated from the slope of the curves shown in Fig. 2 and found to increase with increase in $\mathrm{fv}$, leading to an $\mathrm{S}$-shaped curve in the plot of Fig. 3. The mismatch of the $\alpha$ values for two adjacent fv values was small in the vicinity at $\mathrm{fv}=0$ and 1.0 , but was large in the vicinity of $\mathrm{fv}=0.5$. For example, the difference $(\Delta \alpha)$ between $\mathrm{fv}=0.5$ and 0.7 was $4.86 \times 10^{-6} \mathrm{~K}^{-1}$, while that between $\mathrm{fv}=0.3$ and 0.5 was $2.77 \times 10^{-6} \mathrm{~K}^{-1}$. These results indicate the mixing of coal fly ash with NiCr-based alloy can reduce the $\alpha$ mismatch between constituent layers of FGMs.

Fig. 4 shows a plot of $\Delta \alpha$ against sintering temperature

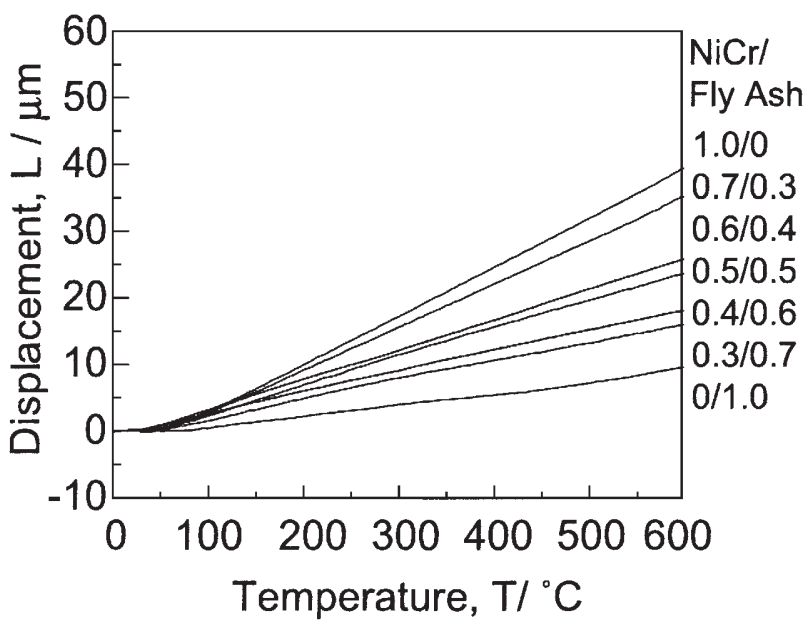

Fig.2 Displacement upon thermal expansion versus temperature for the materials sintered at $1000{ }^{\circ} \mathrm{C}$ as a function of the volume fraction of the coal fly ash to the $\mathrm{NiCr}$-based alloy. for the sintering of various two-layer combinations. Cracking of two adjacent layers was observed by optical microscope when $\Delta \alpha$ between the two layers was more than $4.2 \times 10^{-6} \mathrm{~K}^{-1}$ while no cracks were detected for $\Delta \alpha$ less than $4.0 \times 10^{-6} \mathrm{~K}^{-1}$. The crack-free region in Fig. 4 corresponded to a maximum $(\Delta \alpha \Delta T)$ value of 0.043 at 4.0 $\times 10^{-6} \mathrm{~K}^{-1}(\Delta \alpha)$ and $1080 \mathrm{~K}(\Delta T)$ The minimum number of interlayers necessary to produce the fly ash / $\mathrm{NiCr}$ FGM structure is estimated from eq. (4) to be 2 , thus the interfaces are three, where $\alpha$ values for coal fly ash and $\mathrm{NiCr}$ based alloy are $3.0 \times 10^{-6} \mathrm{~K}^{-1}$ and $12.6 \times 10^{-6} \mathrm{~K}^{-1}$, respectively.

Fig. 5 shows an optical micrograph of a cross-section of the FGMs with two interlayers prepared by sintering at $1000{ }^{\circ} \mathrm{C}$ under the conditions given in Fig. 4. It was confirmed that all the sintered materials were dense

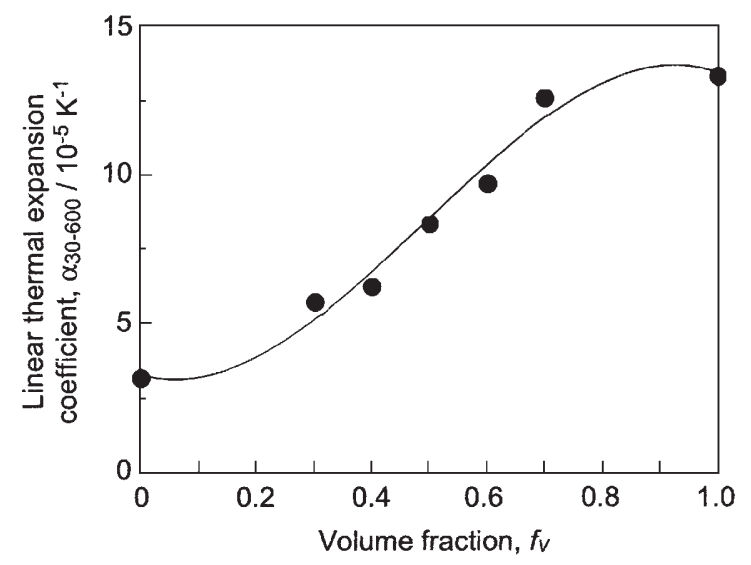

Fig.3 Linear thermal expansion coefficient versus the volume fraction of $\mathrm{NiCr}$-based alloy of coal fly ash sintered at 1000 ${ }^{\circ} \mathrm{C}^{6)}$.

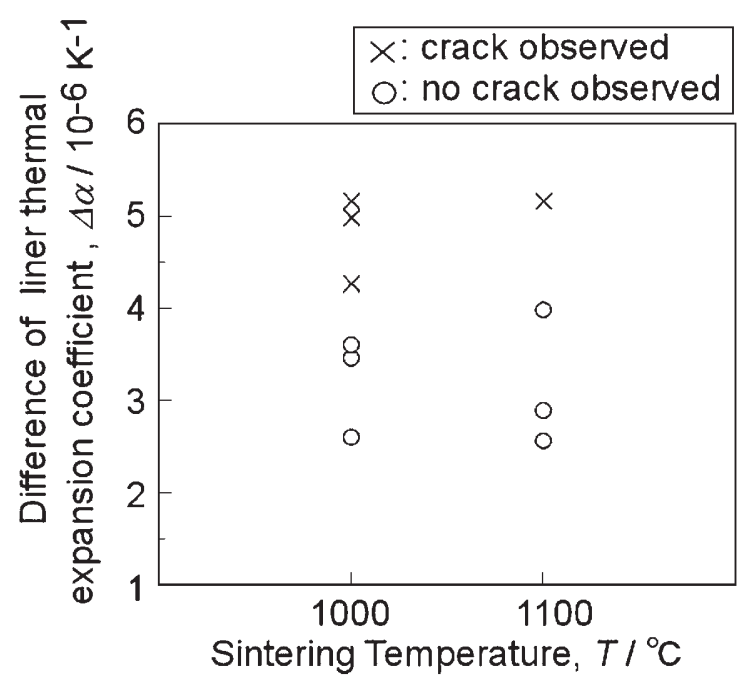

Fig.4 Difference in the linear thermal expansion coefficient $(\Delta \alpha)$ plotted as a function of sintering temperature for the sintering of various two interlayer combinations ${ }^{6}$. 


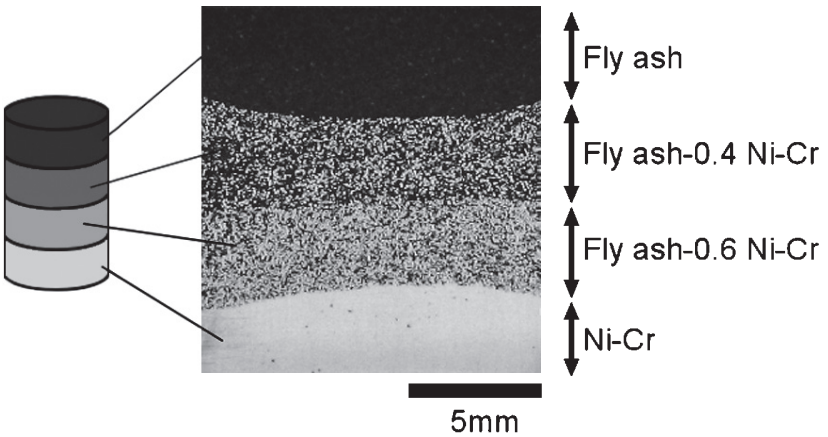

Fig.5 Optical micrograph of a cross-section of the two-interlayer FGMs prepared by sintering at $1000{ }^{\circ} \mathrm{C}$ referring to the criterion shown in Fig. 4, where no cracking was observed for the FGM of (coal fly ash) / (coal fly ash $+0.4 \mathrm{NiCr}$ ) $/$ (coal fly ash $+0.6 \mathrm{NiCr}) /(\mathrm{NiCr})^{6}$.

containing neither cracks nor voids, the composition of which was (coal fly ash) $/$ (coal fly ash $+0.4 \mathrm{NiCr}$ ) $/$ (coal fly ash $+0.6 \mathrm{NiCr}) /(\mathrm{NiCr})$. The difference in the expansion coefficients, $\Delta \alpha$ was $4.0 \times 10^{-6} \mathrm{~K}^{-1}$ between the interlayers of $f v=0$ and 0.4 and also between those of $f v=0.4$ and 0 . A small value of $3.4 \times 10^{-6} \mathrm{~K}^{-1}$ was found for between those of $f v=0.6$ and 1 . These results support the model shown in Fig. 1.

Fig. 6 shows SEM and EDX micrographs for the cross section of the coal fly ash and $0.6 \mathrm{NiCr}$-based alloy mixture sintered at $1000^{\circ} \mathrm{C}$. The small spheres are the $\mathrm{NiCr}$-based alloy particles and their number appeared to increase with an increased $\mathrm{fv}$ of the NiCr-based alloy in Fig. 5. The particles of coal fly ash and NiCr-based alloy did not react with each other. These results support the model in Fig. 1.

To minimize the number of interlayers and prepare a stable FGM from coal fly ash and $\mathrm{NiCr}$-based alloy, it was found $\Delta \alpha \Delta T$ needs to be kept below 0.043 .

Table 3 shows the difference $\Delta T(\mathrm{~K})$ between sintering and room temperatures, the difference $\Delta \alpha\left(\mathrm{K}^{-1}\right)$ in thermal expansion coefficients of constituent layers reported for $\mathrm{FGMs}^{7-15)}$, and the calculated $\Delta \alpha \Delta T$. It is notable that $\Delta \alpha \Delta T$ is less than 0.043 and satisfies the criterion in the present FGMs analysis model.

For simplicity, Fig. 7 shows plots of $\Delta \alpha$ against $\Delta T$ for the values in Table 3. The line drawn shows the relationship of $\Delta \alpha \Delta T=0.043$. The circle on the line corresponds to the condition for preparing stable FGM from coal fly ash and $\mathrm{NiCr}$-based alloy in the present paper. It is noteworthy that the $\Delta \alpha \Delta T$ values estimated from other available FGM reports are less than 0.043 . These results show that the present FGM analysis model can be applied generally to various particulates-based FGMs.
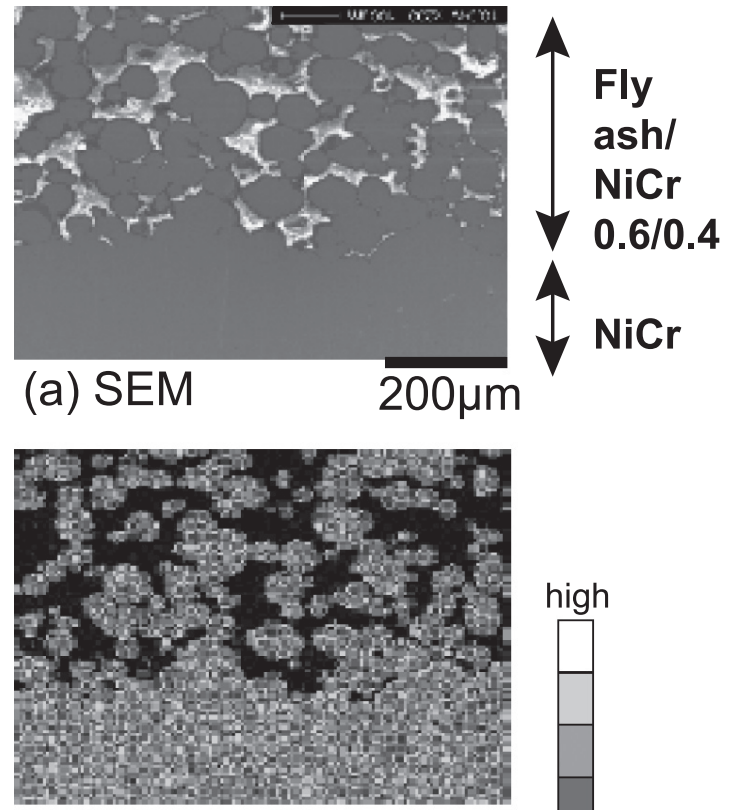

(b) $\mathrm{Ni}$
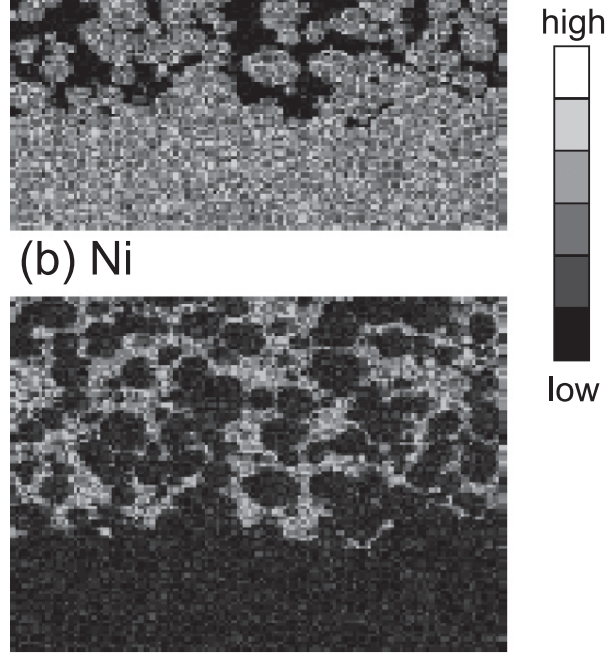

(c) $\mathrm{O}$

Fig.6 SEM and EDX cross sections of the coal fly ash and 0.6 $\mathrm{NiCr}$-based alloy mixture sintered at $1000^{\circ} \mathrm{C}$; (a) SEM, (b) $\mathrm{Ni}$ and (c) $\mathrm{O}$.

\section{Conclusion}

The present study derived a criterion needed to prepare crack-free FGMs using an empirical bimetal model. The linear thermal expansion coefficient was measured for constituent materials, and cracks in the FGMs were inspected upon sintering powder mixtures of coal fly ash and $\mathrm{NiCr}$-based alloy. The criterion was found to hold for the available data of FGMs. The study's results are as follows.

(1) The condition for preparing stable FGM without interlayer cracking is the value for the minimum number of stacked interlayers being less than $\left(\alpha_{\mathrm{A}}-\alpha_{\mathrm{B}}\right) / \Delta \alpha$.

(2) Stable FGMs without interlayer fractures and cracks were fabricated for $\Delta \alpha \Delta T$ less than 0.043 using a powder mixture of coal fly ash and $\mathrm{NiCr}$-based alloy $\left(\Delta \alpha: 4.0 \times 10^{-6} \mathrm{~K}^{-1}, \Delta T: 1080 \mathrm{~K}, \alpha_{\text {coal fly ash }}: 3.0 \times 10^{-6}\right.$ $\left.\mathrm{K}^{-1}, \alpha_{\mathrm{NiCr}}: 12.6 \times 10^{-6} \mathrm{~K}^{-1}\right)$. In this case, the minimum interlayer number was evaluated as 2 . 
Table 3 Difference between sintering and room temperatures and maximum difference in the thermal expansion coefficient for FGMs

\begin{tabular}{ccccc}
\hline Materials & $\begin{array}{c}\text { Difference of } \\
\text { sintering and room } \\
\text { temperature }(\mathrm{K})\end{array}$ & $\begin{array}{c}\text { Maximum difference } \\
\text { of thermal expansion } \\
\text { coefficient }\left(10^{-6} \mathrm{~K}^{-1}\right)\end{array}$ & $\Delta \alpha \Delta \mathrm{T}\left(10^{-2}\right)$ & Reference \\
\hline $\mathrm{Cu} / \mathrm{Mo}$ & 930 & 3.40 & 3.2 & 8 \\
$\mathrm{AlN} / \mathrm{Ni}$ & 980 & 3.50 & 3.4 & 9 \\
$\mathrm{Ti} / \mathrm{Hydroxyapatite}$ & 1080 & 2.04 & 2.2 & 10 \\
$\mathrm{Fly} \mathrm{ash} / \mathrm{NiCr}$ & 1080 & 4.00 & 4.3 & Present work \\
$\mathrm{PSZ} / \mathrm{IN} 100$ & 1130 & 1.77 & 2.0 & 11 \\
$\mathrm{PSZ} / \mathrm{SUS304}$ & 1180 & 2.61 & 3.1 & 12 \\
$\mathrm{TiC} / \mathrm{Ni}{ }_{3} \mathrm{Al}$ & 1280 & 2.30 & 2.9 & 13 \\
$\mathrm{Al}_{2} \mathrm{O}_{3} / \mathrm{ZrO}{ }_{2}$ & 1480 & 1.21 & 1.8 & 14 \\
$\mathrm{C} / \mathrm{SiC}$ & 1980 & 1.00 & 2.0 & 15 \\
$\mathrm{Re} / \mathrm{W}$ & 2177 & 0.73 & 1.6 & 16 \\
$\mathrm{Ir} / \mathrm{W}$ & 2177 & 0.95 & 2.1 & 16 \\
\hline
\end{tabular}

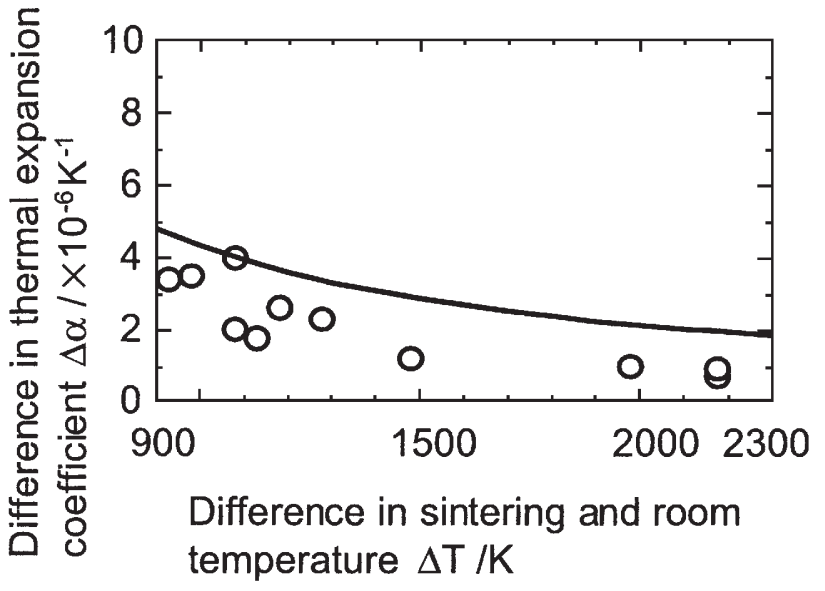

Fig.7 Difference in the thermal expansion coefficient between two adjacent interlayers plotted as a function of the difference between sintering and room temperatures.

(3) $\Delta \alpha \Delta T$ values in the available FGM reports were estimated to be less than 0.043 . This indicates the criterion of $\Delta \alpha \Delta T$ can be generally applied for the preparation of particulates-based FGMs.

\section{Acknowledgment}

We thank Sakae Mishima, Yoshiaki Suzuki, and Kazuki Kikui of the Industrial Research Institute of Tottori Prefecture for mechanical testing.

\section{References}

1) A. Kawasaki and R. Watanabe: "Concept and P/M Fabrication of Functionally Gradient Materials", Ceramics International, 23(1997)73-83.
2) M.M. Gasik: "Industrial Applications of FGM Solution", Materials Science Forum, 423-425(2003) 17-23.

3) S. Uemura: "The Activities of FGM on New Applications", Materials Science Forum, 423-425 (2003) 1-10.

4) A. Kawasaki and R. Watanabe: "Finite Element Analysis of Thermal Stress of the Metal/Ceramics multi-layer Composites with Controlled Compositional Gradients", Nippon Kinzoku Gakkai-si, 51(1987)525529.

5) G. Kaneko, M. Mori, H. Kitagawa, K. Hasezaki, and H. Tanaka: "Preparation and Characterization of Sintered Coal Fly-Ash Bulk Material by Spark Plasma Sinering (SPS)", J. Jpn. Soc. Powder Powder Metallurgy, 53(2006)503-506.

6) K. Hasezaki, A. Nakashita, G. Kaneko, and H. Kakuda: "Sintering Properties of Functionally Graded Materials Using Coal Fly Ash and NiCr-Based Alloy Powder", Materials Transactions, 48(2007)3066-3069.

7) K. Nakano and S. Nishida: "Physical properties about metal matrix FGM of molybdenum and copper", American Society of Mechanical Engineers, Pressure Vessels and Piping Division (Publication) PVP, 302 (1995) 283-289.

8) K. Atarashiya: "Aluminum nitride/metal composites using ultara-fine aluminum particles and their application for joining", Journal of Materials Processing Technology, 54(1995)54-59.

9) C. Chu, Z. Yin, J. Zhu, S. Wang, and P. Lin: 
"Characterization and optimized design of HA-Ti/Ti/ HA-Ti symmetrical functionally graded biomaterial", Functional Graded Materials 2000, Ceramics Transaction, 112(2001)81-88.

10) M. Yuki, Y. Nakanishi, A. Kawasaki, and R. Watanabe: "Fabrication of PSZ/IN100 Functionally Gradient Material on Metal Substrate", Keisyazairyou Symposium (FGM'93), (1993)47-50.

11) H. Yamaoka, M. Yuki, K. Tahara, T. Irisawa, and R. Watanabe: "Fabrication of Sintered Functionally Gradient Material by Dipping Process", Keisyazairyou Symposium (FGM'91), (1991)73-75.

12) L.M. Zhang, R. Yuan, M. Oomori, and T. Hirai: "Residual and working stresses of a $\mathrm{TiC} / \mathrm{Ni}_{3} \mathrm{Al} \mathrm{FGM}$ and its structure optimization", Journal of Materials
Science Letters, 14(1995) 1620-1623.

13) P. Hvizdos, D. Jonsson, M. Anglada, G. Anne, and O. Van Der Biest: "Mechanical properties and thermal shock behaviour of an alumina/zirconia functionally graded material prepared by electrophoretic deposition", Journal of the European Ceramics Society, $27(2007) 1365-1371$.

14) C. Kawai and S. Wakamatsu: "Fabrication of $\mathrm{C} / \mathrm{SiC}$ composites by an electrodeposition/sintering method and the control of the properties", Journal of Materials Science, 31(1996)2165-2170.

15) M. Katoh, H. Horita, and T. Igarashi: "Thermal stress in graded Re/W/Mo and Ir/W/Ta structures for emitters of thermionic converter", Keisyakinouzairyouronbunsyu (FGM'98), (1998)97-103. 